\title{
AQUILES E MÊMNON FACE À MORTE: UM ESTUDO DA CENA DA PSICOSTASIA NA PINTURA DA CERÂMICA ÁTICA
}

\author{
José Geraldo Costa Grillo*
}

RESUMO: O autor estuda as pinturas da cerâmica ática, com a representação da Psicostasia de Aquiles e Mêmnon, respondendo à questão do contexto, no interior do qual ela adquire sentido. Defende a ideia de que ela está imersa na esfera religiosa e ligada ao tema da morte, especificamente ao ideal heroico da bela morte, o qual vem ser o meio de o guerreiro escapar do fim que a morte representa, uma vez que esta morte heroica lhe permite permanecer vivo na memória de seu povo.

PALAVRAS-CHAVE: Arte grega; Pintura; Vasos áticos; Psicostasia; Morte.

\section{ACHILLES AND MEMNON IN THE FACE OF DEATH: A STUDY OF THE DEPICTIONS OF PSYCHOSTASIA IN ATTIC POTTERY PAINTING}

\begin{abstract}
The author studies the Attic pottery paintings, with the depiction of Psychostasia of Achilles and Memnon, answering the question of the context within which it acquires meaning. Defends the idea that it is steeped in religious sphere and linked to the theme of death, specifically to the heroic ideal of the beautiful death, which comes to be the way of the warrior escape the end that death is, since this heroic death lets he stay alive in the memory of his people.
\end{abstract}

KEYWORDS: Greek Art, Painting, Attic vases; Psychostasia; Death.

\section{INTRODUÇÃO}

A palavra Psicostasia, do grego Psychostasía, significa "pesagem das almas", e, no que tange a Aquiles e Mêmnon, refe- 
re-se ao ato de Hermes pesar em uma balança de dois pratos o destino dos dois guerreiros no duelo que estão na iminência travar. A alma do guerreiro que for mais pesada fará seu prato baixar e a ele será imputado o destino da morte, sob os golpes de seu oponente, o vencedor do embate.

As pinturas da cerâmica ática, com a cena da Psicostasia de Aquiles e Mêmnon, começaram a aparecer por volta de 540 a.C. e foram até cerca de 450 a.C., e têm sido estudadas academicamente de meados do século XIX até o final do século XX. A história destes estudos aponta três fases nas quais se buscou, primeiramente, identificar as fontes literárias que teriam inspirado os pintores, para, depois, focar as pinturas como obras de arte e, por fim, tentar compreendê-las em seu contexto de produção, reconstituído por meio dos textos dos autores antigos.

Nesse sentido, este estudo responde à questão do contexto, no interior do qual a Psicostasia adquire sentido. A ideia defendida é a de que ela está imersa na esfera religiosa e ligada ao tema da morte, especificamente ao ideal heroico da bela morte, o qual vem ser o meio de o guerreiro contornar o problema da morte, uma vez que esta morte heroica lhe permite permanecer vivo na memória de seu povo.

\section{TRADIÇÃo LITERÁRIA}

Como os estudos sobre a Psicostasia de Aquiles e Mêmnon relacionam sua iconografia à tradição literária, apresentam-se, em tradução direta dos originais gregos, os principais textos utilizados na historiografia deste tema, a saber, os poemas épicos a Ilíada de Homero, a Etiópida de Arctino de Mileto e a tragédia de Ésquilo a Psicostasia. As obras de Arctino e de Ésquilo se perderam e só podem ser conhecidas de forma fragmentária através de resumos e testemunhos efetuados por autores antigos de períodos posteriores.

\section{A. Iliada}

Na Ilíada, Homero narra uma cena de Psicostasia muito importante para a pesquisa, a saber, aquela referente ao duelo de Aquiles e Heitor. Ela acontece quando Aquiles perseguia Heitor ao redor da muralha de Tróia, que dele fugia tentando 
entrar na cidade. Aquiles impediu por quatro vezes a tentativa de Heitor, ainda que este contasse com a ajuda de Apolo. Para decidir a sorte dos dois guerreiros no duelo que se seguirá, Zeus tomou sua balança e colocou num de seus pratos a Cer ("Destino") de Aquiles e no outro a de Heitor. Se os pratos ficassem equilibrados não haveria vencedor; para tanto, era necessário ser mais pesada uma das Ceres, fazendo baixar o prato. Ao respectivo guerreiro seria imposto o destino da morte. Tal foi o caso de Heitor.

Mas quando pela quarta vez chegaram às fontes,

o Pai levantou a balança de ouro

e nela colocou os dois destinos da mui dolorosa morte:

de um lado o de Aquiles e de outro o de Heitor domador de cavalos.

Tomou-a pelo meio e a alçou: baixou o dia fatal de Heitor, que partiu para o Hades. Abandonou-o, então, Febo Apolo (HOMERO Ilíada, XXII, 208-213).

\section{B. Etiópida}

Conforme o resumo de Proclo ${ }^{1}$, em sua Crestomatia, Arctino (cerca de 775-744 a.C.) narrou em sua Etiópida os eventos relacionados a Aquiles e Mêmnon. A Psicostasia não é mencionada; mas tão somente a chegada do príncipe Etíope, Mêmnon, a Tróia, o aviso de Tétis de tal acontecimento a Aquiles, a morte de Antíloco e o duelo entre eles, no qual Mêmnon perece.

Mêmnon, o filho de Eos, vestindo uma panóplia trabalhada por Hefesto, vem em ajuda dos Troianos contra seus inimigos. Tétis informa seu filho sobre Mêmnon. Ao suceder da batalha, Antíloco sucumbe ante Mêmnon; Aquiles, então, mata Mêmnon (PROCLO, Crestomatia, p. 33).

\section{Psicostasia}

Da Psicostasia de Ésquilo, sobreviveram alguns testemunhos (cf. NAUCK, 1856, p. 69), que além de atestarem a existência da peça, apresentam a cena da "pesagem das almas" e mencionam alguns personagens nela presentes.
1. Proclo, como autor desta obra, pode ser tanto um gramático grego de origem e data desconhecidas, quanto o filósofo neoplatônico, que viveu aproximadamente entre 421-485 d.C. 
A primeira informação sobre esse momento vem do gramático de Alexandria, Aristônico (época de Augusto), o qual em um de seus escólios sobre a Ilíada, além de testificar a composição de uma Psicostasia por parte de Ésquilo, menciona a cena de Zeus pesando na balança as almas de Mêmnon e Aquiles. "Ésquilo, que tinha o hábito de se referir às almas, diz ele, compôs a Psicostasia, na qual Zeus está pesando na balança as almas de Mêmnon e Aquiles" (ARISTÔNICO, Escólio sobre a Ilíada VIII, 70).

O filósofo grego Plutarco (cerca de 40-120 d.C.), em seu tratado, Como deve o jovem inteirar-se da poesia, ao citar a Psicostasia de Aquiles e Heitor na Ilíada de Homero, também testifica a composição da obra e acrescenta dois personagens à cena, Tétis e Eos, as mães de Aquiles e Mêmnon respectivamente.

Ésquilo acomodou uma tragédia inteira a este mito e a intitulou Psicostasia, na qual, com certeza, estavam próximas dos pratos da balança de Zeus Tétis de um lado e de outro Eos, rogando em favor dos filhos combatendo em duelo (PLUTARCO, Obras morais, 17A).

O retórico grego Júlio Polux (século II d.C.), por fim, em seu Vocabulário, dá elementos da cenografia da peça de Ésquilo ao esclarecer que: "Do alto do teologéion, que fica acima da cena, aparecem os deuses; como Zeus e aqueles ao seu redor na Psicostasia" (POLUX, Vocabulário, IV, 130).

Apesar do estado fragmentário das informaçōes fornecidas pelos autores antigos, é possível ter certa ideia de alguns dados. A começar pelo poema homérico, há a indicação clara de dois espaços e duas temporalidades: Zeus encontra-se no Olimpo, enquanto Aquiles e Heitor estão no campo de batalha em Tróia, e Zeus realiza a Psicostasia num momento anterior àquele do duelo entre os dois guerreiros.

A cena da Psicostasia de Aquiles e Mêmnon pressupõe as mesmas divisões espaciais e temporais. Os dois espaços estão muito bem delimitados. Primeiramente, pela informação de Plutarco de que Ésquilo elaborou sua peça a partir do poema homérico, no qual Zeus está pesando as almas de Aquiles e Mêmnon no Olimpo enquanto os dois guerreiros encontram-se duelando no campo de batalha; depois, pela disposição do 
cenário apresentada por Polux. O teologéion é o lugar onde os deuses se reúnem para fazer uso da palavra. No caso da peça, devia ser uma tribuna, que Ésquilo indica situar-se no Olimpo ao colocá-la acima da cena, isto é, a decoração posta ao fundo, atrás do proscênio, no qual é representado o combate de Aquiles e Mêmnon.

No que tange às temporalidades, as delimitaçóes entre elas não são tão simples. Os textos de Aristônico e de Plutarco permitem deduzir que as mesmas foram mantidas. Todavia, no cenário apresentado por Polux, há duas possibilidades: Ésquilo pode tanto ter apresentado a pesagem das almas num primeiro momento e o duelo em outro subsequente, ou os dois momentos simultaneamente, pressupondo que a plateia os saberia distinguir cronologicamente.

Os personagens que atuam em cada um dos espaços podem ser do mesmo modo precisados. No Olimpo, Aristônico afirma ser Zeus o portador da balança, na qual pesa as almas de Aquiles e Mêmnon, e Plutarco diz estar certo de que Tétis, mãe de Aquiles, e Eos, mãe de Mêmnon, encontram-se ao lado do prato com a alma de seu respectivo filho, rogando a Zeus em seu favor. No campo de batalha, estão Aquiles e Mêmnon combatendo em duelo.

\section{HisTÓRIA DA PESQUISA}

Friedrich Gottlieb Welcker (1849), em seu estudo sobre o Ciclo Épico, estava preocupado, acima de tudo, em preencher duas lacunas deixadas pelo estado fragmentário dos textos dos autores antigos, a saber, o conteúdo e composição de cada uma das obras deste ciclo. Levando em conta todos os textos antigos disponíveis, ele concluiu ser verossímil supor ter Arctino incluído em sua Etiópida a cena da Psicostasia de Aquiles e Mêmnon. "De Ésquilo e do conjunto da arte antiga, diz ele, devemos concluir que a Psicostasia da batalha de Aquiles com Hector foi também utilizada para esta outra grande batalha decisiva reportada por Arctino" (WELCKER, 1849, p. 175).

Arctino, então, teria sido o primeiro a adaptar a Psicostasia homérica à lenda de Aquiles e Mêmnon. Esta hipótese do grande filólogo alemão tornou-se referencial para a pesquisa posterior, tanto para sua aceitação como para sua refutação. 
2. Veja-se o Catálogo, logo mais abaixo, no item 6 .
As ideias de Welcker fazem-se presente no estudo Johannes Overbeck (1857) dedicado às obras de arte relacionadas às lendas heroicas tebanas e troianas. "As obras de arte, diz ele, são para o meu objetivo mais do que um meio para a poesia, elas são o objetivo principal de meu trabalho" (OVERBECK, 1857 , p. 492). Todavia, apesar desta afirmação, que coloca a arte como objeto primordial de seu estudo, ele também considera "as imagens como meio de reconstrução da poesia" (OVERBECK, 1857, p. 492). Assim, diante do estado fragmentário da Etiópida, ele examina dois vasos áticos (cf. Cat. $\mathrm{n}^{\text {os }} 3$ e 5$)^{2}$ com a representação da Psicostasia de Aquiles e Mêmnon, visando demonstrar que tal cena integrava o argumento desta obra de Arctino.

Leopold Schmidt (1857) questionou a hipótese da presença de uma Psicostasia na Etópida de Arctino. Mesmo admitindo certa probabilidade quanto a isso, entende que deva ser posta de lado tal ideia; pois, de fato, a Etiópida, como conhecida pelo resumo de Proclo, apresenta apenas o duelo entre Aquiles e Mêmnon, enquanto que Ésquilo foi o último poeta trágico a tratar deste tema e os autores posteriores da Antiguidade atestam que sua peça apresentava justamente a Psicostasia do duelo entre os dois guerreiros. Constatação que faz de Ésquilo o primeiro a adaptar a Psicostasia homérica para este novo tema.

Com o objetivo de comentar a cena de Psicostasia em um cálice da antiga coleção de Giampietro Campana, agora pertencente ao Museu do Louvre (cf. Cat. no 9), ele destaca uma importante mudança: já não é mais Zeus que segura a balança e realiza a pesagem das almas, como na tradição literária, mas sim Hermes. "As representaçôes artísticas conservadas deste tema, diz ele, conferiram a Hermes este encargo, e é muito provável que o fizeram seguindo um tipo proposto pela poesia" (SCHMIDT, 1857, p. 119).

Nesta primeira fase da pesquisa, fica subjacente, portanto, uma ideia que perpassará as pesquisas posteriores, a saber, a da estreita relação de dependência entre as imagens e os textos; visto que, nesse caso, a poesia conhecida pelo pintor é aquela da Psicostasia de Ésquilo.

Com Hermann Luckenbach (1880) inaugura-se uma segunda fase da pesquisa que revisa esta relação entre a arte e os textos. As imagens não são mais vistas como ilustrações dos 
textos antigos, e mesmo quando um artista demonstra em sua obra conhecer um determinado texto, ele não intenta uma tradução fiel do mesmo.

O que acontece e se forma em seu espírito, o que ele entendeu do relato dos poetas ou viu no teatro, é o que ele pinta; mesmo que ele se refira à poesia pelo conteúdo, ele compõe a cena à sua maneira. Ele escolhe o momento e o tipo de representação, tanto suprimindo quanto acrescentando, sempre conforme a pintura the exige tal feito (LUCKENBACH, 1880, p. 494).

No que concerne à Psicostasia de Aquiles e Mêmnon, Luckenbach examina quatro vasos áticos (cf. Cat. $\mathrm{n}^{\text {os }} 1,3,5$ e 9), cujas representaçôes ele entende ter alguma relação com a Psicostasia de Ésquilo, pressupondo ter este preservado em sua peça uma tradição mais anriga.

Na mesma linha, Carl Robert (1881), preocupado com a relação dos pintores de vasos do século $\mathrm{V}$ a.C. com as tragédias áticas, entende que a pintura da Psicostasia do Pintor de Cleófrades (cf. Cat. no 3 ) é do mesmo tipo daquela descrita na peça de Ésquilo. "De maneira segura, diz ele, esta cena é atestada pela Psicostasia de Ésquilo, conforme as informaçóes fidedignas de Aristônico e Plutarco" (ROBERT, 1881, p. 143).

Robert admite com isso certas ligações da arte com a poesia; mas, ressalta também as discrepâncias, como o caso de Ésquilo apresentar Zeus pesando as almas na balança e as obras de arte que colocam Hermes nesta tarefa. Agindo assim, os artistas transferiram a Hermes a função de Psicostata (gr. Psychostátes, "pesador de alma"), a qual era exclusiva de Zeus na tradição literária. Não se trata, portanto, de uma relação de dependência entre o artista e a poesia trágica; pois, ao final de seu percurso sobre este tema, ele chega a uma conclusão justamente oposta.

A análise mais profunda, diz ele, demonstrou que não se pode realmente comprovar em nenhum caso a ação dos dramas áticos nas pinturas de vasos do século $\mathrm{V}$, e que, portanto, não se tem o direito, como acontece tantas vezes, de postular o uso dos vasos de figuras vermelhas para a reconstrução dos dramas (ROBERT, 1881, p. 148). 
Arthur Schneider (1886), considerando que acima do artista, de sua arte e técnica paira um universo espiritual, afirma que aquilo que é posto aos olhos pelo artista é o resultado de suas motivações.

O artista, diz ele, é movido por interesses, quer dizer, ele seleciona os eventos de um lugar que se tornou caro a ele e aos outros. Estes eventos se dividem em duas classes: em primeiro lugar, aqueles que integravam o complexo lendário, o qual certamente proporcionava uma interpretação em um todo de grande importância; segundo, aqueles de representação particularmente singela e significativa na poesia, que adquiriram grande popularidade, tanto em toda a Grécia, quanto em áreas específicas, e imprecionavam de modo especial as pessoas que se relacionavam com intimidade (SCHNEIDER, 1886, p. 5).

Esta constatação o leva a entender que o episódio chave ou o momento crucial de um mito constituem apenas o essencial apreendido e apresentado pelo artista, e não a versão exata dada por um poeta determinado. Com isso em mente, ele examina três vasos áticos (cf. Cat. $\mathrm{n}^{\mathrm{os}} 1,3$ e 4), apontando as possíveis relações das representações pictóricas com a Psicostasia de Ésquilo, que podem ajudar na interpretação, mas destacando também as diferenças, sobretudo, aquela de Hermes como Psicostata.

Em um estudo dedicado ao Trono Ludovisi, Franz Stuniczka (1911) aborda também o Trono de Boston, no qual há um relevo esculpido com uma cena de Psicostasia, motivo que o leva a tratar do assunto e a apresentar as obras de arte conhecidas até então com esta temática. Dentre as oito elencadas por ele, as cinco primeiras são vasos áticos (cf. Cat. ${ }^{\text {os }} 1,3,4,6$ e 9). Sintetizando as ideias dos três autores anteriores, Studniczka entende ter Ésquilo adaptado em sua peça a cena da Psicostasia de Aqulies e Heitor para a de Aquiles e Mêmnon; todavia, ressalta o caráter distintivo das obras de arte apontando uma diferença fundamental, a saber, a substituição de Zeus por Hermes como o realizador da pesagem das almas.

Na Ilíada, diz ele, Zeus pesou, supostamente, antes do duelo decisivo entre Aquiles e Heitor, as Ceres de ambos os heróis em sua balança de ouro [...]. Desde algum tempo, alega- 
-se com frequência, que Ésquilo, em sua Psicostasia, imitou este ponto colcando Zeus pesando as almas [...] de Aquiles e Mêmnon, que combatem um contra o outro. [...]. A tradição pictórica deste tema leva certamente em conta o exposto por Ésquilo, mas difere significativamente dele ao colocar Hermes pesando as almas na balança e não Zeus (STUDNICZKA, 1911, p. 131-132).

Em desacordo com essa maneira de conceber a relação entre as imagens e a peça de Ésquilo, Lacey Davis Caskey e John Davidson Beazley (1963) retomam a hipótese de a Etiópida de Arctino ter inspirado as representações dos artistas. Ao analisar o vaso do Museu de Belas Artes de Boston com a cena da Psicostasia de Aquiles e Mêmnon (cf. Cat. no 6), os autores elencam nove obras de arte com este tema; dentre os quais, sete vasos áticos, incluso o de Boston (cf. Cat. $\mathrm{n}^{\text {os }} 1,2$, 3, 4, 6, 8 e 9). Partindo da constatação de que em todos esses vasos é Hermes e não Zeus o realizador da pesagem das almas, eles entendem que estas imagens indicam não ter sido Ésquilo o criador desta cena de Psicostasia, mas sim Arctino.

Estas imagens, dizem eles, mostram que a Psicostasia de Aquiles e Memnon não foi inventada por Ésquilo, mas adotada por ele a partir de um poema anterior. $\mathrm{O}$ qual não pode ter sido outro que o épico atribuído a Arctino de Mileto, que contou a história da Guerra de Tróia, do ponto no qual a Ilíada a deixou, e foi chamado Etiópida porque tinha por tema o rei dos etíopes, Mêmnon (CASKEY; BEAZLEY, 1963, p. 45).

O paradigma estabelecido por estes autores permaneceu em vigor até o início dos anos 1990. Assim, os estudos de Annelise Kossatz-Deissmann (1981; 1992), Gérard Siebert (1990) e Rainer Vollkommer (1992), seguindo o modelo geral do Lexicon Iconographicum Mythologiae Classicae, recolheram para cada personagem o conjunto das fontes literárias disponíveis, catalogaram todas as obras artísticas conhecidas e realizaram um comentário iconográfico de obra a obra ou de um conjunto delas quando agrupadas sob um mesmo tema. ${ }^{3}$ Desses autores, somente Kossatz-Deissmann (1992) aborda a cena da Psicostasia de Aquiles e Mêmnon em seu comentário alegando que esta deriva daquela de Aquiles e Heitor na Ilíada.
3. Em seu estudo sobre Aquiles, KossatzDeissmann (1981) estuda sete vasos áticos (cf. Cat. $\mathrm{n}^{\text {os }} 1,2,3,4,6,8$ e 9$)$ agrupados no tema da "Psicostasia de Aquiles e Mêmnon"; enquanto que no segundo, sobre Mêmnon (cf. KOSSATZDEISSMANN, 1992), estuda oito vasos áticos (os mesmos sete anteriores, acrescidos do estâmno de Melbourne; cf. Cat. $n^{\circ}$ 7) agrupados no tema da "Psicostasia", destacando quando a mesma se "combina com o duelo de Aquiles e Mêmnon" (cf. Cat. nos 2, 4 e 9). Do mesmo modo, Siebert (1990), em seu estudo sobre Hermes, analisa sete vasos (cf. Cat. nos 2, 3, 4, 6, 7, 8 e 9) agrupados no tema Cenas de psicostasia. Por fim, Vollkommer (1992) estuda sete vasos sob o tema da Cerostasia ("pesagem das Ceres"), subdivididos conforme as representaçôes trazem a "Cer na forma de um ser alado" (cf. Cat. n ${ }^{\text {os }} 1$ e 4) ou a "Cer na forma de um guerreiro" (cf. Cat. n ${ }^{\text {os }}$ 2, 3, 6, 8 e 9). 
4. Knittlmayer estuda oito vasos (cf. Cat. n ${ }^{\text {os }} 1,2,3$, $4,5,6,7$ e 8) com a cena da Psicostasia de Aquiles e Mêmnon.
A mudança veio somente no final desta década com a obra de Brigitte Knittlmayer (1997), na qual tem o propósito de estudar as representações das lendas do ciclo troiano segundo o contexto histórico concernido.

Para explicar a popularidade e o alcance da representação pictórica de um mito, diz ela, é fundamental situá-la no contexto de emergência de cada época. Para este contexto, conta não só a história política, mas também as circunstâncias históricas em sentido mais amplo, incluindo os aspectos culturais e sociais, bem como a história das mentalidades (KNITTLMAYER, 1997, p. 16).

Esta nova abordagem de Knittlmayer inaugura a terceira e mais recente fase da pesquisa; pois, a relação entre a obra do artista e os textos literários tal qual concebida anteriormente foi definitivamente abandonada. Trata-se, agora, de usar a tradição literária como fonte suscetível de informar a pesquisa sobre a significação das representaçōes mitológicas. Os textos trazem dados preciosos sobre a consciência que a classe aristocrática tinha de si mesma e das transformaçôes sociais, que de alguma maneira impactaram os artistas e suas obras. Nesse sentido, ela procura detectar os valores aristocráticos que fornecem indícios para a compreenção das imagens.

Com isso em mente, Knittlmayer organiza sua obra em torno de cinco temas do ciclo troiano: a) a cena da Presbeía ("embaixada"), na qual as ideias de indivíduo e de comunidade aparecem como uma consequência da reforma de Clístenes; b) a cena do Resgate de Heitor, que demostra estar permeada pelos temas da festa e dos presentes, elementos expressivos modo de vida aristocrático; c) as cenas de Partida, duelo e morte do guerreiro, que colocam o herói mítico como guerreiro exemplar; d) as cenas de Aquiles e Troilo, que os apresentam como paradigmas do hoplita e do cavaleiro; e, por fim, e) a cena da Psicostasia, onde se coloca a relação do agir humano com o poder dos deuses. ${ }^{4}$

A conclusão geral a que chega é que a aristocracia ateniense legitimava seus valores tanto transportando o presente no passado heroico das lendas troianas, quanto atualizando seus mitos para seu tempo atual. 
No que respeita ao tema da Psicostasia, Knittlmayer interpreta as representações pictóricas "de acordo com as ideias de destino e da relação dos deuses na vida das pessoas", tais quais se constatam nas fontes literárias do final do período arcaico e início do clássico; pois, entende que "o pensamento de que a existência humana depende do poder divino, é igualmente abordado nas representações da Psicostasia" (KNITTLMAYER, 1997, p. 100 e 107).

Observa-se, na literatura desta época, diz ela, a ligação frequente do motivo da balança com termos do direito, o que também contribuiu para a conexão das representações pictóricas da Psicostasia com certos aspectos morais. Os deuses são vistos, portanto, como uma autoridade moral, que decide sobre a vida dos heróis em particular e das pessoas em geral (KNITTLMAYER, 1997, p. 107-108).

Nesse contexto, o tema da Psicostasia está imerso, segundo ela, na polaridade de ideias que apregoam a misericórdia dos poderes divinos para com os seres humanos de um lado, e, de outro, a crença em deuses que intervêem de maneira punitiva na vida das pessoas, seja para reprovar, seja para impor o infortúnio. Em suma, ideias que acentuam a nulidade do planejamento humano.

\section{A Psicostasia de Aquiles e Mêmnon}

Diante dessas questōes colocadas pelas pesquisas anteriores, este estudo inicia-se com a análise das cenas da Psicostasia de Aquiles e Mêmnon, não em função de suas relações com as versões da tradição literária, mas sim a partir das composições que lhes são próprias, buscando identificar os esquemas iconográficos utilizados pelos pintores para contar sua história; para, em seguida, verificar o significado dessas representações num contexto cultural específico, reconstituído através da tradição literária.

\section{A. Análise iconográfica}

Considerando que a característica fundamental da Psicostasia seja uma divindade pesando as almas de dois guer- 
reiros em uma balança, julga-se plausível pressupor terem os pintores composto seus esquemas iconográficos a partir deste motivo.

Tomadas em seu conjunto, as representaçôes da Psicostasia de Aquiles e Mêmnon organizam-se em cinco esquemas iconográficos. Os quatro primeiros são organizados em torno de Hermes Psicostata, uma vez ser ele o pesador das almas. No quinto, Hermes está ausente, porque se refere a um momento anterior ao da pesagem das almas, no qual Zeus é o personagem principal.

No esquema I, Hermes está pesando as almas diante de Zeus, indicando passar-se a cena no Olimpo. No esquema II, Hermes está pesando as almas entre dois guerreiros, implicando na justaposição dos espaços, o do Olimpo e com o do campo de batalha, bem como das temporalidades a eles inerentes. No esquema III, Hermes está pesando as almas entre duas mulheres, passando-se a cena presumivelmente no Olimpo. No esquema IV, Hermes está sozinho pesando as almas, o que não permite que espacialidade e temporalidade possam ser determinas. $\mathrm{O}$ esquema $\mathrm{V}$ apresenta uma representação diferente, na qual Tétis e Eos estão intercedendo a Zeus por seus respectivos filhos, Aquiles e Mêmnon.

Os esquemas I e II variam na composição segundo alguns motivos. No primeiro, há dois tipos: IA - O grupo central está ladeado por mulheres (Mulher/Hermes-Zeus/ Mulher); IB - O grupo central está acompanhado de uma mulher (Hermes-Zeus/ Mulher). No segundo, há também dois tipos: IIA - O grupo central está acompanhado de outros personagens (Guerreiro-Hermes-Guerreiro/Mulher-Mulher-Zeus); IIв - O grupo central está sozinho (Guerreiro-Hermes-Guerreiro).

\section{Sinopse dos Esquemas Iconográficos da Psicostasia}

\begin{tabular}{|c|}
\hline I - Hermes pesando as almas diante de Zeus: \\
\hline IA - Grupo central ladeado por mulheres (Cat. $\mathrm{n}^{\circ} 1$ ) \\
\hline IB - Grupo central acompanhado de uma mulher (Cat. nos 3 e 7 ) \\
\hline II - Hermes pesando as almas entre dois guerreiros: \\
\hline IlA - Grupo central acompanhado de outros personagens (Cat. $n^{\circ} 2$ ) \\
\hline IlB - Grupo central sozinho (Cat. $\left.n^{\circ} 4\right)$ \\
\hline III - Hermes pesando as almas entre duas mulheres (Cat. $n^{\circ s} 6$ e 9 ) \\
\hline IV - Hermes pesando as almas sozinho (Cat. $\left.\mathrm{n}^{\circ} 8\right)$ \\
\hline V - Outra representação: Tétis e Eos rogando a Zeus (Cat. $n^{\circ} 5$ ) \\
\hline
\end{tabular}


O Pintor da Enlutada do Vaticano foi o primeiro a representar a Psicostasia de Aquiles e Mêmnon, criando o esquema I, em seu tipo IA (cf. Cat. no 1). O grupo central é composto por Zeus à esquerda e Hermes à direita. Diante de Zeus, sentado em um banco, segurando o raio com a mão direita, Hermes segura a balança com a mão direita, em cujos pratos estão as almas dos dois guerreiros personificadas na forma de dois pequenos seres alados (eídola). Ladeiam o grupo central duas mulheres gesticulando; a da esquerda tem o braço esquerdo na mesma posição do de Zeus e a da direita tem os dois braços meio estendidos, indicando que ambas também estão fazendo uso da palavra. A balança encontra-se desequilibrada, com o prato direito abaixado. O pintor indica, assim, tanto o guerreiro que sofrerá o destino de morte, quanto quem são os outros personagens, ou seja, o eídolon da esquerda representa Aquiles e o da direita Mêmnon, a mulher à esquerda é Tétis e a da direita Eos, que rogam a Zeus por seus respectivos filhos.

O Pintor de Cleófrades, ainda no esquema I, criou o tipo Iв (cf. Cat. no 3), no qual o grupo central está acompanhado de uma mulher. O grupo central é composto por Zeus à esquerda e Hermes à direita. Diante de Zeus, em pé segurando o raio com a mão direita e o cetro com a esquerda, Hermes segura o caduceu com a mão esquerda e a balança com a mão direita, em cujos pratos estão as almas dos dois guerreiros personificadas na forma de dois pequenos hoplitas. A balança encontra-se desequilibrada, com o prato direito abaixado, indicando que Mêmnon sofrerá o destino da morte. À direita, encontra-se Eos, com braço direito estendido, rogando a Zeus por seu filho.

Seguindo tipo Ів, о Pintor Hemónax (cf. Cat. $\mathrm{n}^{\text {o }}$ 7) também representa o grupo central composto por Zeus à esquerda e Hermes à direita, acompanhado de uma mulher. Diante de Zeus, em pé segurando o raio com a mão direita e o cetro com a esquerda, Hermes segura o caduceu com a mão esquerda e a balança com a mão direita, em cujos pratos estão as almas dos dois guerreiros (Os eídola estão atualmente apagados). A balança encontra-se desequilibrada, com o prato esquerdo abaixado, indicando que Mêmnon sofrerá o destino da morte. À direita, encontra-se Tétis, segundando um bastão com a mão esquerda e com braço direito estendido, rogando a Zeus por seu filho. 
O esquema II, em seu tipo IIA, foi criado pelo Pintor Epícteto (cf. Cat. no 2). O grupo central é composto por Hermes ladeado por Aquiles à esquerda e Mêmnon à direita. Hermes segura o caduceu com a mão esquerda e a balança com a mão direita, em cujos pratos estão as almas dos dois guerreiros personificadas na forma de dois pequenos hoplitas. Aquiles e Mêmnon são representados duelando com a mesma postura, ambos em pé e completamente armados, apontando as lanças uma ao outro, indicando que o duelo está ainda indefinido quanto à vitória de um deles. A balança, todavia, encontra-se desequilibrada, com o prato direito abaixado, indicando que Mêmnon sofrerá o destino da morte. Num segundo registro, à direita do grupo central, encontram-se Eos e Tétis com os braços estendidos rogando por seus filhos a Zeus, sentado no trono, segurando o raio com a mão esquerda e o cetro com a direita.

O Pintor de Safo, ainda no esquema II, criou o tipo IIв (cf. Cat. no 4; veja-se, mais abaixo, a Figura 1), no qual o grupo central é representado sozinho. Hermes, ladeado por Aquiles à esquerda e Mêmnon à direita, segura a balança com a mão esquerda, em cujos pratos estão as almas dos dois guerreiros personificadas na forma de dois pequenos seres alados. Aquiles e Mêmnon são representados duelando com a mesma postura, ambos em pé e completamente armados, apontando as lanças uma ao outro, indicando que o duelo está ainda indefinido quanto à vitória de um deles. A balança, todavia, encontra-se desequilibrada, com o prato direito abaixado, indicando que Mêmnon sofrerá o destino da morte.

O esquema III foi criado pelo Pintor de Siracusa (cf. Cat. $n^{\circ}$ 6). Hermes, ladeado por Tétis à esquerda e Eos à direita, segura o caduceu com mão esquerda e a balança com a direita, em cujos pratos estão as almas dos dois guerreiros personificadas na forma de dois pequenos hoplitas. A balança encontra-se desequilibrada, com o prato direito abaixado, indicando que Mêmnon sofrerá o destino da morte. Tanto Tétis quanto Eos têm os braços estendidos rogando a ele por seus filhos. Um pintor anônimo (cf. Cat. no 9) seguiu este esquema, com a diferença de que Tétis e Eos não estão rogando a Hermes por seus filhos e sim se afastando dele.

O Pintor de Oritia (cf. Cat. no 9), por fim, criou uma representação diferente, na qual Hermes está ausente devido ao 
fato de ela se passar em um momento anterior ao da pesagem das almas, quando Tétis e Eos intercediam a Zeus por seus filhos. Com todos os personagens nomeados por inscrições, Zeus, sentado em um trono, segurando o raio com a mão direita e o cetro com esquerda, é ladeado por Eos à esquerda e Tétis à direita, ambas com um de seus braços estendidos, indicando estarem rogando por seus filhos, Mêmnon e Aquiles respectivamente.

Os pintores narram a história da Psicostasia de Aquiles e Mêmnon em três tempos sucessivos: T1 - Tétis e Eos intercedendo a Zeus; T2 - Hermes pesando as almas; e T3 - Aquiles Mêmnon duelando. Os quais se passam em dois espaços diferentes: E1 - Olimpo (T1-2) e E2 - Campo de batalha (T3).

Todavia, em suas estratégias narrativas, eles, na maioria das vezes, justapóem tanto os tempos quantos os espaços. Quando eles preservam a unidade de tempo e espaço, representando um único momento em uma história particular, a pesquisa moderna convencionou chamar esta estratégia de monocênica, e de sinóptica, quando combinam vários momentos ou episódios diferentes de uma história em uma única representação (cf. SHAPIRO, 1994).

A estratégia monocênica foi utilizada no esquema $\mathrm{V}$ Tétis e Eos intercedendo a Zeus (T1; E1) e no esquema IV - Hermes pesando as almas sozinho (T2; E1); enquanto a sinóptica no esquema I - Hermes pesando as almas diante de Zeus acompanhado de uma ou duas mulheres (T1-2; E1), no esquema II - Hermes pesando as almas entre dois guerreiros (T2-3; E1-2) e no esquema III - Hermes pesando as almas entre duas mulheres (T1-2; E1).

\section{B. Aquiles e Mêmnon face à morte}

Apesar da inovação e do avanço na pesquisa que a obra de Brigitte Knittlmayer (1997) representa, é possível interpretar a cena da Psicostasia de Aquiles e Mêmnon de maneira diferente, que estabeleça seu significado num contexto mais preciso da religião grega.

Knittlmayer percebeu a ligação estreita que une num todo coerente as cenas de armamento, duelo e morte do guerreiro; porém, não explorou este elemento em sua contextualização, identificando apenas o caráter exemplar de guerreiro 
que a aristocracia ateniense idealizava. Inclusive, ao explorar a cena da Psicostasia de Aquiles e Mêmnon, ela a tratou separadamente da cena de duelo entre os dois guerreiros e, na contextualização, não foi além de situá-la no universo religioso, apontando estar o agir humano sob o domínio do poder divino.

O problema com esta concepção é que a interpretação da cena da Psicostasia não deve ser feita de maneira independente daquela do duelo à qual ela se refere; do mesmo modo que a cena de duelo só adquire sentido pleno quando posta em relação com as cenas de armamento e retorno do guerreiro, com quais forma um todo. Além disso, é preciso considerar o fato de estas cenas integrarem os valores guerreiros da sociedade ateniense, os quais, por sua vez, estão imersos na esfera religiosa (cf. GRILLO, 2009 e 2010).

Este conjunto de cenas é composto por três momentos nodais da atividade guerreira. O primeiro é o do armamento do guerreiro, no qual ele, ao receber e vestir a armadura, que fora outrora de seu pai, torna-se um guerreiro. A cena de Aquiles, recebendo a armadura de Tétis, sua mãe, pertence a esse gênero. $\mathrm{O}$ segundo momento compreende as representações de dois guerreiros combatendo em duelo. O jovem grego, tornado um guerreiro no ato de seu armamento, deve realizar, agora, os feitos que o integrarão entre os melhores. O combate em duelo é a demonstração de que o guerreiro não é apenas jovem, belo e viril, mas, acima de tudo, corajoso e capaz, em suma, um herói. Esse é o caso das cenas dos duelos entre Páris e Menelau, Enéias e Diomedes, Ájax e Heitor, Aquiles e Heitor, e Aquiles e Mêmnon. O último momento engloba as representações do retorno do guerreiro morto, que se referem aos cuidados que se devem ter com os mortos para realização dos ritos funerários. Nesse gênero, inserem-se as cenas de Sono e Morte carregando o corpo de Sarpédon e de Ájax carregando o corpo de Aquiles.

Estas cenas ligam-se, portanto, aos valores guerreiros da sociedade ateniense de modo geral e em particular ao ideal heroico da bela morte, um tema crucial da religião grega.

$\mathrm{Na}$ Grécia antiga, guerra e religião estavam estreitamente relacionadas, e, ao estudar essa relação, é necessário considerar, conforme Louise Bruit-Zaidman (1999), não apenas as instituições religiosas e os ritos, mas, também, as representações 
que estruturam o imaginário social. Constatando permitirem essas representações a compreensão da natureza e da significação das práticas religiosas, ela destaca que os deuses permeiam todos os aspectos da vida social, todas as atividades, privadas ou públicas, da vida dos cidadãos, inclusas aí, a concepção e a realização da guerra.

Jean-Pierre Vernant (1996 e 2001) estudou, nesse sentido, o tema morte, destacando em seu interior o ideal heroico da bela morte; o qual vem a ser o fundamento da concepção $\mathrm{da}$ atividade guerreira dos atenienses nos séculos VI-V a.C. A ideia de bela morte, segundo ele, refere-se ao conjunto de representaçóes e de valores atribuídos à morte, que orienta a maneira de ser e de agir do guerreiro.

Em Homero, a bela morte designa o jovem guerreiro que, na flor da idade, na plenitude de sua virilidade, morre, corajosamente, valentemente, em batalha. A ideia de bela morte remete, portanto, a um ideal heroico, no qual essa maneira de morrer confere ao guerreiro morto uma iniciação ao conjunto de qualidades, prestígios e valores pelos quais, ao longo de suas vidas, os melhores, aqueles que compõem a elite heroica, entram em competição.

Aquiles, o melhor dos Aqueus, e Heitor, o melhor entre os Troianos, são os representantes máximos desse ideal no poema. Aquiles, diante de dois "destinos" (gr. kêras) escolhe aquele que conduz a uma vida breve, a morte que, em troca, lhe trará a "glória imperecível", em detrimento daquele de uma vida longa sem ela; Heitor, mesmo convencido de que perecerá diante de Aquiles, deseja, em sua condição de guerreiro, transformar sua morte em "glória imperecível" (HOMERO, Iliada, IX, 410-416 e XXII, 304-305).

A bela morte, dessa maneira, eleva o guerreiro, ameaçado pela morte a desaparecer, a ser esquecido, a um estado de glória. A busca por essa glória reveste-se de pleno sentido em uma cultura em que cada um existe em função dos outros, ou seja, sob os olhos e pelos olhos dos outros, na qual a reputação, o renome, é tudo o que conta para uma pessoa. Se a morte é o esquecimento; existir, ao contrário, é, seja vivo ou morto, encontrar-se reconhecido, estimado, honrado, em suma, glorificado.

O guerreiro, nesse estado, ainda que fisicamente morto, permanece vivo. Tido entre os melhores, como herói, ele pas- 
sa a ser objeto de um canto de louvor, de um relato de seus feitos, de seu destino glorioso. Exaltado, o herói é inscrito na memória social, passando a viver na lembrança de todos que o admiram.

Assim, o ideal heroico, segundo Vernant, constitui uma das respostas que os gregos elaboraram face ao problema do declínio inexorável das forças, do envelhecimento contínuo, da fatalidade da morte. Essa idealização da morte é, portanto, a tentativa heroica de não cair na obscuridade do esquecimento, de se fundir na massa indistinta dos anônimos, de afastar o horror do caos, do informe, da falta de sentido, e de afirmar a permanência social desta individualidade humana que, por natureza, deve, necessariamente, desaparecer. Eis a solução que o ideal heroico dá à condição humana: encontrar na morte o meio de ultrapassar essa condição, vencer a morte pela própria morte, dando a ela um sentido que não tem, pois a morte, quanto a isso, é totalmente desprovida.

Essa concepção do ideal heroico da bela morte inscreve a atividade guerreira na esfera religiosa; na qual, os três momentos nodais da atividade guerreira, o armamento do guerreiro, os duelos e o retorno do guerreiro morto em batalha, são ritos de passagem. No primeiro, realiza-se um rito de iniciação, no qual o jovem grego adquire o estatuto de guerreiro. No segundo, o guerreiro encontra-se em uma fase de latência, pois ao mesmo tempo em que já foi admitido como guerreiro, ainda não é, necessariamente, um herói, uma condição que dependerá de seus feitos. Por fim, no terceiro, realiza-se um rito de separação, no qual o guerreiro sai do estatuto de cadáver e passa ao de belo morto.

Nesse contexto, o duelo de Aquiles e Mêmnon implica tanto o modo de cada um desses guerreiros atuar na guerra, quanto como enfrenta a possibilidade da morte. No duelo, o jovem ateniense, agora um guerreiro, deve, no acontecer da guerra, provar sua força física, sua excelência, mas, também, sua força moral, colocando sua vida em risco de morte. Essa é uma concepção da morte que integra os valores guerreiros da sociedade ateniense e é justamente neste contexto que a Psicostasia dever compreendida, visto ser um duelo sua única razão de existir, o qual ela tem a finalidade de decidir o desfecho.

Nas pinturas da cerâmica ática, com o tema da Psicostasia de Aquiles e Mêmnon, a decisão divina sobre o desti- 
no destes guerreiros é enfatizada principalmente pelo fato de Hermes, o deus Psicopompo ("Acompanhante das almas"), em quase todas elas (cf. Cat. $\mathrm{n}^{\text {os }} 1-8$ ), estar realizando a pesagem das almas. O fato de ser ele e não Zeus o Psicostata, em nada diminui a ideia de que "a presença de um imortal é apropriada em caso de mortes importantes" (VERMEULE, 1979, p. 160), como são as dos dois heróis em duelo.

A ligação da cena da Psicostasia com a do duelo é feita de duas maneiras pelos pintores. Primeiramente, quanto eles as justapõem sinopticamente na mesma pintura (cf. Cat. nos 2 e 4; Figura 1), representando Hermes pesando as almas entre dois guerreiros (Esquema II). Segundo, quando pintam as duas faces do vaso com Psicostasia de um lado e o duelo de outro (cf. Cat. nos 7 e 9; GRILLO, 2009, p. 317 e 321, fig. 141 e 145). A implicação com o ideal heroico da bela morte evidencia-se por nas duas vezes que as cenas são justapostas o duelo estar ainda indefinido quanto à vitória de um dos oponentes, pois os dois estão se enfrentando como a mesma postura, isto é, ambos estão em pé e apontando suas lanças um ao outro na mesma posição, o que indica estarem em iguais condiçôes para vencer. Nesta condição em que ambos se encontram, eles se enfrentam corajosamente como iguais e em mútuo respeito, vendo um no outro a morte como um perigo real.

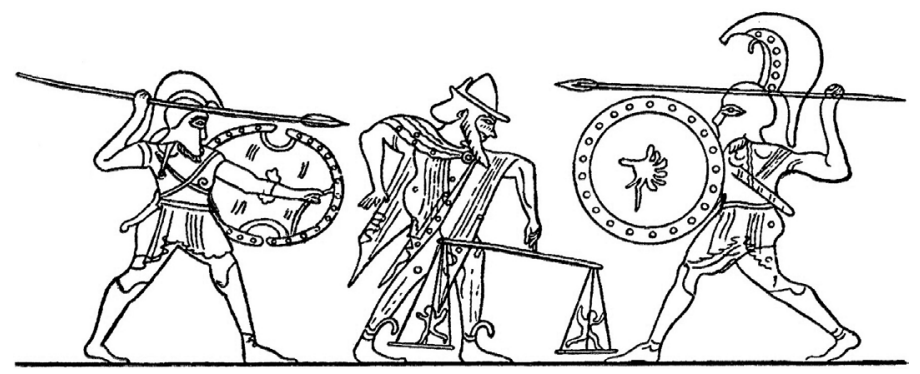

Figura 1. (cf. Cat. no 4; desenho do autor)

Não é possível saber se, nesses casos, os pintores quiseram dizer ou ao menos insinuar terem Aquiles e Mêmnon consciência de que seus destinos estavam por ser ou se já o foram decididos na balança divina, seja pela possibilidade de suas mães os informarem a esse respeito daquilo que sabiam de antemão, seja porque os pintores, ao justaporem as cenas de maneira sinóptica, visaram criar uma nova cena na qual pesagem das almas aconteceu efetivamente aos olhos dos envolvidos. 
A Psicostasia deve, assim, ser contextualizada na esfera religiosa, porém forçosamente ligada ao tema da morte, e não a uma ideia de destino que implique a anulação da vontade humana. Mesmo no passado, quando a doutrina da predestinação foi utilizada nos estudos clássicos, seu propósito era o de gerar consolo e não uma atitude passiva na vida frente a um destino que se impunha às pessoas (cf. WEBER, 1918). Pois, mesmo que a Psicostasia signifique "a confirmação supranatural do inevitável” (VERMEULE, 1979, p. 160), o Aquiles e o Mêmnon da cena de Psicostasia na pintura cerâmica encontram-se na mesma condição de o Aquiles e de o Heitor no poema homérico. Eles enfrentam o destino da morte com a mesma atitude. Este destino não lhes impunha medo; pelo contrário, eles consciente e voluntariamente o escolhiam, por visualizarem nele um caminho alternativo para algo maior, a glória, dada pelo poema épico, que os tornariam heróis, homens renomados, memoráveis, eternizados na lembrança de seu povo, em suma, imortais.

\section{CONSIDERAÇŌES FINAIS}

A história da pesquisa da Psicostasia de Aquiles e Mêmnon demonstra que, de meados do século XIX ao final do século XX, os estudos passaram por três fases com concepções próprias aos postulados acadêmicos de cada época. Uma história muito instrutiva para que a pesquisa continue sua trajetória; pois, a riqueza de sua diversidade e de suas inovaçóes faz vislumbrar que com o passar do tempo mudanças podem ocorrer novamente.

Se a compreensão dos estudos anteriores, a concepção dos esquemas iconográficos, a vinculação com a esfera religiosa em geral e com o ideal heroico da bela morte em particular, bem como com a cena duelo, propostas neste estudo, forem procedentes, uma nova interpretação da Psicostasia de Aquiles e Mêmnon torna-se, então, viável.

Não se trata, no entanto, de uma quarta fase da pesquisa e de uma nova abordagem; pelo contrário, ocorre apenas uma maneira diferente de conceber o tema na mesma linha de pesquisa que a obra de Brigitte Knittlmayer inaugurou, e, da qual, o autor se reconhece devedor. 


\section{Catálogo}

1. Dino. Figuras negras. Cerveteri. Pintor da Enlutada do Vaticano. Cerca de 540 a.C. Viena, Museu de História da Arte, inv. IV3619.

Bibliografia: BEAZLEY, 1956, p. 140, no 3; CASKEY; BEAZLEY, 1963, p. 45, no 2; KNITTLMAYER, 1997, p. 139, no E1, pr. 23.2-3; KOSSATZ-DEISSMANN, 1981, p. 173, no 799, pr. 135; 1992, p. 452, no 17; LUCKENBACH, 1880, p. 617, no I; SCHNEIDER, 1886, p. 141, no A; STUDNICZKA, 1911, p. 132, no a; VOLLKOMMER, 1992, p. 19$20, n^{\circ} 57$.

2. Cálice. Figuras vermelhas. Cerveteri. Pintor Epícteto. Cerca de 510 a.C. Roma, Museu Nacional Etrusco de Villa Giulia, inv. 57684.

Inscrição: EPIKTETOS EGRAPHSEN.

Bibliografia: BEAZLEY, 1963, p.72, no 24; CASKEY; BEAZLEY, 1963, p. 45, no 2; KNITTLMAYER, 1997, p. 140, $\mathrm{n}^{\circ}$ E2, pr. 24.1; KOSSATZ-DEISSMANN, 1981, p. 174, $\mathrm{n}^{\circ}$ 804, pr. 136; 1992, p. 452, no 19; SIEBERT, 1990, p. 338, no 623; VOLLKOMMER, 1992, p. 20, no 60, pr. 11.

3. Cratera com volutas. Figuras vermelhas. Corneto. Pintor de Cleófrades. Cerca de 500-490 a.C. Paris, Coleção das Medalhas da Biblioteca Nacional, inv. 385.

Bibliografia: BEAZLEY, 1910, p. 42, no 4; 1963, p. 186, $n^{\circ}$ 50; CASKEY; BEAZLEY, 1963, p. 45, no 4; KNITTLMAYER, 1997, p. 140, no E6; KOSSATZ-DEISSMANN, 1981, p. 173-174, no 803; 1992, p. 452, no 20; LUCKENBACH, 1880, p. 617, no H; OVERBECK, 1857, p. 527, no 65, pr. 22.9; ROBERT, 1881, p. 143-145; SCHNEIDER, 1886, p. 142-143; SIEBERT, 1990, p. 338, no 624; STUDNICZKA, 1911, p. 132, no c; VOLLKOMMER, 1992, p. $20, n^{\circ} 61$.

4. [Figura 1] Lécito. Figuras negras. Cápua. Pintor de Safo. Cerca de 490 a.C. Londres, Museu Britânico, inv. B639.

Inscrições: Sem sentido.

Bibliografia: CASKEY; BEAZLEY, 1963, p. 45, no 3; KNITTLMAYER, 1997, p. 140, nº E4; KOSSATZ-DEISSMANN, 
1981 , p. 173 , no 798 , pr. $135 ; 1992$, p. 452 , no 18 , pr. $233-$ 234; SCHNEIDER, 1886, p. 141, no B; SIEBERT, 1990, p. 338, no 622, pr.250; STUDNICZKA, 1911, p. 132, no b, fig. 54; VOLLKOMMER, 1992, p. 20, nº 58, pr. 11.

5. Cratera em sino. Figuras vermelhas. Agrigento. Pintor de Oritia. Cerca de 480 a.C. Palermo, Museu Arqueológico Regional, inv. V779.

Inscriçōes: HEOS, IEUS, THETIS.

Bibliografia: BEAZLEY, 1963, p. 496, no 5; KNITTLMAYER, 1997, p. 140, no E5; LUCKENBACH, 1880, p. 617, no D; OVERBECK, 1857, p. 527, no 66, pr. 22.10.

6. Estâmno. Figuras vermelhas. Cumas. Pintor de Siracusa. Cerca de 480 a.C. Boston, Museu de Belas Artes, inv. 10.177. Bibliografia: BEAZLEY, 1963, p. 518, no 1; CASKEY; BEAZLEY, 1963, p. 44-46, no 147, pr. 82-83; KNITTLMAYER, 1997, p. 140, $\mathrm{n}^{\circ}$ E3, pr. 24.2; KOSSATZ-DEISSMANN, 1981, p. 173 , no 800 , pr. $135 ; 1992$, p. 453 , no 22; SIEBERT, 1990, p. 338, no 626; STUDNICZKA, 1911, p. 133, no d, fig. 55; VOLLKOMMER, 1992, p. 20, no 62.

7. Estâmno. Figuras vermelhas. Pintor Hermónax. Cerca de 470-460 a.C. Melbourne, Galeria Nacional de Vitória, inv. D64.1980.

Lado A: Psicostasia; Lado B: duelo.

Bibliografia: BEAZLEY, 1963, p. 129, no 25; KNITTLMAYER, 1997, p. 140, no E7; KOSSATZ-DEISSMANN, 1992, p. 452, no 21; SIEBERT, 1990, p. 338, nº 625, pr. 250.

8. Ânfora. Figuras vermelhas. Pintor de Nícon. Cerca de 470460 a.C. Paris, Museu do Louvre, inv. CA2243.

Bibliografia: BEAZLEY, 1963, p. 651, no 11; CASKEY; BEAZLEY, 1963, p. 45, no 7; KNITTLMAYER, 1997, p. 140, $\mathrm{n}^{\circ}$ E8; KOSSATZ-DEISSMANN, 1981, p. 173, no 802; KOSSATZ-DEISSMANN, 1992, p. 453, no 23; SIEBERT, 1990 , p. 338, no 628, pr. 250; VOLLKOMMER, 1992, p. $20, \mathrm{n}^{\circ} 63$.

9. Cálice. Figuras vermelhas. Etrúria. Sem atribuição. Cerca de 450 a.C. Paris, Museu do Louvre, inv. G399. 
Lado A: Psicostasia; Lado B: duelo.

Bibliografia: CASKEY; BEAZLEY, 1963, p. 45, no 8; KOSSATZ-DEISSMANN, 1981, p. 173, no 801, pr. 135; 1992, p. 453, no 24; LUCKENBACH, 1880, p. 617, no G; SCHMIDT, 1857, p. 118-123; SIEBERT, 1990, p. 338, $n^{\circ}$ 627; STUDNICZKA, 1911, p. 133-134, no e, fig. 56; VOLLKOMMER, 1992, p. 20, nº 64, pr. 12.

\section{REFERÊNCIAS BIBLIOGRÁFICAS}

\subsection{Autores antigos}

ARISTÔNICO. Escólio sobre a Iliada VIII, 70. In: ARISTONICI. Perì semeion iliádos. Reliquiae emendatiores. Edidit Ludovicus Friedlander. Gottingae: Libraria Dieterichiana, 1853.

HOMERO. Iliada. In: Homeri Ilias. Edidit Guilielmus Dindorf. Editio quinta correctior quam curavit Carl Hentze. Pars II. Iliadis XIII-XXIV. Lipsiae: B. G. Teubner, 1894.

NAUCK, Augustus (Recensvit). Tragicorum graecorum fragmenta. Lipsiae: B. G. Teubner, 1856.

PROCLO. Crestomatia. In: Epicorum graecorum fragmenta. Collegit disposuit commentarium criticum. Adiecit Godofredus Kinkel. Lipsiae: B. G. Teubner, 1877.

PLUTARCO. Obras morais. In: PLUTARCHI CHAERONENSIS. Moralia. Volumen I. Recognovit Gregorius N. Bernardakis. Lipsiae: B. G. Teubner, 1888.

POLUX. Vocabulário. In: POLLUCIS. Onomasticon. Fasciculus prior. Edidit et adnotauit Ericus Bethe. Lipsiae: B. G. Teubner, 1900.

\subsection{Bibliografia}

BEAZLEY, John Davidson. Attic black figure vase painters. Oxford: Clarendon, 1956. Attic red figure vase painters. 3 volumes. Oxford: Clarendon, 1942. Second edition, 1963.

BRUIT-ZAIDMAN, Louise. Guerre et réligion en Grèce à l'époque classique. In: BRUN, Patrice (Coord.). Guerres et so- 
ciétés dans les mondes grecs (490-322). Paris: Du Temps, 1999. p. 127-148.

CASKEY, Lacey Davis; BEAZLEY, John Davidson. Attic vase paintings in the Museum of Fine Arts, Boston. Part III. London; Boston: Oxford University; Museum of Fine Arts, 1963.

GRILLO, José Geraldo Costa. A Guerra de Tróia no imaginário ateniense: sua representação nos vasos áticos dos séculos $V I-V$ a.C. 2009. Tese (Doutorado em Arqueologia) - Museu de Arqueologia e Etnologia, Universidade de São Paulo, São Paulo. Disponível em: <http://www.teses.usp.br/teses/disponiveis/71/71131/tde-13042009-164013/>. Acesso em: janeiro 2014 .

A Guerra de Tróia no imaginário ateniense: sua representação nos vasos áticos dos séculos VI-V a.C. Phoînix, 16, p. 32-49, 2010.

KNITTLMAYER, Brigitte. Die attische Aristokratie und ihre Helden. Untersuchungen zu Darstellungen des trojanischen Sagenkreises im 6. und frühen 5. Jahrhundert v. Chr. Heidelberg: Archäologie und Geschichte, 1997.

KOSSATZ-DEISSMANN, Annelise. Achilleus. In: Lexicon Iconographicum Mythologiae Classicae. Volume I. Zürich; München: Artemis, 1981. p. 37-200.

Memnon. In: Lexicon Iconographicum Mythologiae Classicae. Volume VI. Zürich; München: Artemis, 1992. p. 448-462.

LUCKENBACH, Hermann. Das Verhältniss der griechischen Vasenbilder zu den Gedichten des epischen Kyklos. Leipzig: B. G. Teubner, 1880.

OVERBECK, Johannes. Die Bildwerke zum thebischen und troischen Heldenkreis. Stuttgart: Ebner und Seubert, 1857.

ROBERT, Carl. Bild und Lied. Archäologische beiträge zur geschichte der griechischen Heldensage. Berlin: Weidmannche Buchhandlung, 1881.

SHAPIRO, Harvey Alan. Myth into art: poet and painter in classical Greece. London: Routledge, 1994.

SCHMIDT, Leopold. Psicostasia. Tazza del museo Campana. Annali dell'Instituto di Corrispondenza Archeologica, 29, p. 118-123, 1857. 
SCHNEIDER, Arthur. Der troische Sagenkreis in der ältesten griechischen Kunst. Leipzig: Wilhelm Engelmann 1886.

SIEBERT, Gérard. Hermes. In: Lexicon Iconographicum Mythologiae Classicae. Volume V. Zürich; München: Artemis, 1990. p. 285-387.

STUDNICZKA, Fraz. Das Gegenstück der Ludovisischen „Thronlehne“. Jarbuch des Kaiserlich Deutschen Archäologischen Instituts, 26, p. 50-96, 97-192, 1911.

VERMEULE, Emily. Aspects of death in early Greek art and poetry. Berkeley: University of California, 1979.

VERNANT, Jean-Pierre. La belle mort et le cadavre outragé. In: L'individu, la mort, l'amour: soi-même et l'autre en Grèce ancienne. Paris: Gallimard, [1982] 1996. p. 41-79.

2001.

La mort heroüque chez les Grecs. Paris: Pleins Feux,

VOLLKOMMER, Rainer. Ker. In: Lexicon Iconographicum Mythologiae Classicae. Volume VI. Zürich; München: Artemis, 1992. p. 14-23.

WEBER, Frederick Parkes. Aspects of death and correlated aspects of life in art, epigram, and poetry: contributions towards and anthology and an iconography of the subject. New York: Paul B. Hoeber, 1918.

WELCKER, Friedrich Gottlieb. Der epische cyclus oder die homerischen Dichter. 2 - Die Gedichte nach Inhalt und Composition. Bonn: Eduad Weber, 1849.

Recebido em março de 2014. Aprovado em julho de 2014. 
